\title{
THE BRITISH JOURNAL OF NUTRITION
}

\section{DIRECTIONS TO CONTRIBUTORS}

Papers submitted for publication in the British Journal of Nutrition should be as concise as possible. Economy of space should not, however, be achieved by suppressing useful results. Authors are invited to preserve experimental results too extensive for publication but deemed of importance, and to indicate in the paper submitted their willingness to make such results available to others.

Papers should be accompanied by a signed statement to the effect that the author accepts the conditions laid down in Directions to Contributors. Special attention is directed to the sections below about the preparation of the typescript, and care in this matter will hasten publication.

The Editors will return any typescript that does not conform to these conditions.

Communications. Papers submitted for publication should be sent to DrS. K. Kon (British Journal of Nutrition), National Institute for Research in Dairying, Shinfield, nr Reading. Orders for reprints should be addressed to The University Press, Cambridge.

General. Submission of a paper to the Editorial Board will be held to imply that it represents the results of original research not previously published; that it is not under consideration for publication elsewhere; and that if accepted for the British Journal of Nutrition it will not be published elsewhere in the same form, in English or any other language, without the consent of the Editorial Board.

Contributors who reside outside Great Britain are requested to nominate somebody in Great Britain willing to correct their proofs. Papers from such contributors should be accompanied by a statement of the number of reprints required.

Authors' names should be given without titles or degrees. Women are requested to give one Christian name in full to avoid confusion. The name and address of the laboratory where the work was performed should be given. Any necessary descriptive material about the author, e.g. Beit Memorial Fellow, should appear in parentheses after the author's name, or at the end of the paper, and not in the form of a footnote.

Typescripts should carry the name and address of the person to whom the proof of the paper is to be sent and should give also a shortened version of the paper's title, not exceeding forty-five letters and spaces in length, suit. able for a running title in the published pages of the work.

Form of Papers Submitted for Publication. The onus of preparing a paper in a form suitable for sending to press lies in the first place with the author. Authors should consult a current issue in order to make themselves familiar with the practice of the British Journal of Nutrition as to typographical and other conventions, use of cross-headings, lay-out of tables, etc. Attention to these and other details (mentioned below) in the preparation of the typescript before it is sent to the Editors will shorten the time required for publication: the need for undue amounts of editorial revision caused by badly prepared typescript will lead to delay in publication. Papers on specialized aspects of the subject should be so presented as to make them intelligible, without undue difficulty, to the ordinary reader of the Journal. Sufficient information should be given to permit repetition of the published work by any competent reader of the fournal.

Papers should be in double-spaced typing on one side of sheets of uniform size with large margins. Top copies only should be submitted, packed flat. The paper should be written in English, the spelling being that of the Oxford English Dictionary, and should, in general, be divided into the following parts. (a) Introductory paragraph: it is not now customary to introduce a paper with a full account of the relevant literature, but the introductory paragraph should help the reader by indicating briefly the nature of the question asked and the reasons for asking it. The answer obtained should be indicated if it is possible to do so shortly. (b) Experimental methods adopted: with chemical papers the experimental part will normally appear towards the end, but with other types of publication Methods should appear after the introduction. (c) Results: these should be given as concisely as possible, with the help of figures or tables. (d) Discussion: it is desirable that the presentation of the results and the discussion of their significance should be considered separately. (e) Summary: each paper must close with a summary not more than $5 \%$ of the length of the previous text. This summary should aim at giving in the third person a picture in miniature of the entire article. The past tense should be used in referring to the author's experimental work. The present tense may be used where reference to existing knowledge is necessary, or where the author is stating what is shown or concluded. The change of tense should clearly differentiate the author's contribution from what is already known. The sequence in the summary should be the same as that in the paper. It is desirable to divide the summary into a series of numbered paragraphs or sentences giving, where relevant, the following information: a succinct account of the experimental work with essential facts about apparatus, chemicals, methods and animals; the results, singling out new information; the conclusions from the results. ( $f$ ) References: these should be given in the text thus: Barnett \& Robinson (1942), (Culbertson \& Thomas, 1933); where a paper to be cited has more than two authors, the names of all the authors should be given when reference is first made, e.g. (Osborne, Mendel \& Ferry, 1919); subsequent citations should appear thus (Osborne et al. 1919). Where more than one paper by the same authors has appeared in one year the reference should be given as follows: Osborne \& Mendel $(1914 a)$; Osborne \& Mendel (1914 $b)$; or Osborne \& Mendel $(1914 a, b) ;($ Osborne \& Mendel, 1914a,1916; Barnett \& Robinson, 1942). At the end of the paper references 
should be given in alphabetical order according to the name of the first author of the publication quoted, names with prefixes being entered under the prefix, and should include the author's initials; the title of the paper should not be included. Titles of journals should be abbreviated as in the World List of Scientific Periodicals (1952: 3rd ed. Oxford University Press). Examples of such abbreviations will be found in the current numbers of the British Journal of Nutrition and useful lists have recently been published in the Journal of Physiology $(1952,116,1)$, by the Biological Council (A List of Abbreviations of the Titles of Biological Journals, obtainable from H. K. Lewis \& Co. Ltd., 136 Gower Street, London, W.C. 1, 2s. 6d.) and by the Royal Society (A List of British Scientific Publications, 1950: Cambridge University Press, 28. 6d.). References to books and monographs should include the town of publication and the name of the publisher, as well as the date of publication and the number of the edition to which reference is made. Thus:

Barnett, J. W. \& Robinson, F. A. (1942). Biochem. J. 36, 364.

Culbertson, C. C. \& Thomas, B. H. (1934). Rep. Ia agric. Exp. Sta. 1933-4, p. 51.

Doisy, E. A., Somogyi, M. \& Shaffer, P. A. (1923). J. biol. Chem. 55, $\mathrm{xxxi}$.

Fairey, N. H. (1938). Nature, Lond., 142, 1156.

Hennessy, D. J. (1941). Industr. Engng Chem. (Anal.), 13, 216.

King, H. (1941). J. chem. Soc. p. 338.

Osborne, T. B. \& Mendel, L. B. (1914a). J. biol. Chem. 17, 325.

Osborne, T. B. \& Mendel, L. B. (1914b). J. biol. Chem. 18, 1. Osborne, T. B. \& Mendel, L. B. (1916). Biochem. J.10, 534. Osborne, T. B., Mendel, L. B. \& Ferry, F. L. (1919). J. biol. Chem. 37, 233.

Starling, E. H. (1915). Principles of Human Physiology, 2nd ed. London: J. and A. Churchill.

Statistical Treatment of Results. In general it is not necessary to publish all the individual results of replicated tests. A statement of the number, their mean value and some appropriate measure of their variability is usually sufficient.

The methods of analysis followed should be indicated, but statistical details, such as tables of analysis of variance, should be given only if they are relevant to the discussion. A statement that the difference between the mean values of two groups of data is statistically significant should include an indication of the level of significance attained.

Illustrations. Illustrations, which should be approximately twice the size of the finished block, should each be on a separate sheet, packed flat and bearing the author's name. Diagrams should be in indian ink and should be drawn on plain white paper, Bristol board or faintly bluelined paper. Curves based on experimental results should carry clear indications of the experimentally determined points. Letters, numbers, etc., should be written lightly in pencil. On the back of each figure should be written the author's name and the title of the paper. Legends should be typed separately from the illustrations, each on a separate sheet, and numbered correspondingly with the relevant illustration. Figures should be comprehensible without reference to the text. For photographs glossy prints are required; clips should not be used and care should be taken to avoid heavy pressure when writing on the backs.

Tables. Tables should carry headings describing their content and should be comprehensible without reference to the text. The dimensions of the data, e.g. g/ $/ 100 \mathrm{ml}$., should be given at the top of each column and not repeated on each line of the table. Tables should not normally be included in the body of the text, but should be typed on separate sheets. Their approximate position in the text should be indicated.

Chemical Formulas. These should be written as far as possible on a single horizontal line. With inorganic substances, formulas may be used, particularly in the experimental portion, at the discretion of the editors. With salts it must be stated whether or not the anhydrous material is used, e.g. anhydrous $\mathrm{CuSO}_{4}$, or which of the different crystalline forms is meant, e.g. $\mathrm{CuSO}_{4} \cdot 5 \mathrm{H}_{2} \mathrm{O}, \mathrm{CuSO}_{4} \cdot \mathrm{H}_{2} \mathrm{O}$.

Description of Solutions. Solutions of common acids, bases and salts are preferably defined in terms of normality (N) or molarity (M), e.g. $\mathrm{N}-\mathrm{HCl} ; 0 \cdot 1 \mathrm{M}-\mathrm{NaH}_{2} \mathrm{PO}_{4}$. The term '\%' must be used in its correct sense, i.e. $\mathrm{g} / 100 \mathrm{~g}$ of solution. $10 \% \mathrm{HCl}$ means $10 \mathrm{~g}$ of hydrogen chloride in $100 \mathrm{~g}$ of aqueous solution, and should never be used to indicate a tenfold dilution of laboratory concentrated hydrochloric acid. For 'per cent by volume', i.e. $\mathrm{ml} . / 100 \mathrm{ml}$., the term ' $\%(v / v)$ ' may be employed. To indicate that a given weight of substance is contained in $100 \mathrm{ml}$. of solution, the term ' $\%(w / v)$ ' may be used.

Nomenclature of Vitamins. The following names have been adopted by the Commission for the Reform of Nomenclature in Biological Chemistry of the International Union of Pure and Applied Chemistry and have been accepted by the Editors of the British Journal of Nutrition:

\section{Present name}

Vitamin $\mathrm{D}_{2}$ or calciferol

Vitamin $\mathrm{D}_{3}$

Vitamin $\mathbf{E}$

Vitamin $B_{1}$, aneurin or thiamine

Vitamin $\mathrm{B}_{2}$ or riboflavin

Vitamin $\mathrm{PP}$, niacinamide or

nicotinamide

Vitamin $\mathrm{B}_{12}$

Vitamin $\mathbf{B}_{12 b}$

Vitamin $\mathbf{B}_{\mathbf{1 2 0}}$

Vitamin $\mathrm{C}=$ ascorbic acid
Name adopted

Ergocalciferol*

Cholecalciferol*

$\alpha$-, $\beta$ - and $\gamma$-tocopherol

Thiamine

Riboflavin

Nicotinamide $\dagger$

Cyanocobalamin $\ddagger$ Hydroxocobalamin $\ddagger$ Nitritocobalamin $\ddagger$ Ascorbic acid
The Editors of the British Journal of Nutrition wish to retain the old more comprehensive names vitamin $D$,

* This name has the advantage of permitting other D vitamins, derived from 7-dehydrosterols, to be named by analogy through the use of the appropriate prefix.

$\dagger$ In addition, the Editors of the British Journal of Nutrition propose always to use nicotinic acid and not niacin.

¥ This name is recommended for adoption because it conforms to Werner's nomenclature for cobalt co-ordina. tion complexes, and hecause it provides a system of terminology which may be extended, by analogy, to many modified cobalamins. 
vitamin $E$, vitamin $B_{1}$, vitamin $B_{12}$ and vitamin $C$ to cover the biological activity where more than one active substance is or may be concerned.

The names vitamin $A\left(A_{1}, A_{2}\right)$ pantothenic acid, biotin, $p$-aminobenzoic acid and choline remain unchanged.

The names for vitamin $K$, the pyridoxin group, inositol and the folic-acid group have not yet been settled.

Nomenclature of Micro-organisms. Bacteria. Scientific names of bacteria should be binomials, the generic name only with a capital, and should be underlined once (for italic) in the typescript. Names for new species or genera, or new combinations of generic and specific names, should be formed in accordance with the International Bacteriological Code published in $J$. Bact. 1948, 55, 287, and (in 1949) in Congr.int. Microbiol. Iv (1948), Copenhagen, p. 587. Wherever possible the names of recognized species should be those used in Topley \& Wilson's Principles of Bacteriology and Immunity (1955: 4th ed. London: Edward Arnold and Co.) and in M.R.C. Memor. no. 21, 1948 (List of Species Maintained in the National Collection of Type Cultures). However, where authors wish for good reasons to use some other name (e.g. one used in Bergey's Manual of Determinative Bacteriology, 1948: 6 th ed. London: Baillière, Tindall and Cox), the Topley \& Wilson name should be inserted in parentheses at the first citation thus: Serratia marcescens (Chromobacterium prodigiosum).

A name must be given in full at the first mention in a paper; in subsequent mention the generis name may be abbreviated, but the abbreviation must be unambiguous. Single letter abbreviations should, in general, be avoided (thus: Staph. aureus, Strep. pyogenes, not S. aureus, $S$. pyogenes). When the generic name is used to define a group it should have a capital but should not be italicized; trivial names, or generic names used as adjectives, should not have capitals or be italicized. Examples of "trivial names" are: staphylococci, streptococci, and meningococci or meningococcus (generic name is Neisseria). Staphylococcus and Streptococeus are generic names and the following passage illustrates the correct usage. 'This investigation is concerned with Salmonella enteritidis, because this Salmonella is important as a cause of disease in man and, because of experimental salmonella infections in the mouse, it is the most easily controlled. Tests with staphylococci, including Staph. aureus, have not contributed to the understanding of susceptibility to staphylococal infection.'
Microfungi should be designated as in Ainsworth \& Bisby's A Dictionary of the Fungi (1954: 4th ed. Kew: Commonwealth Mycological Institute).

Other Nomenclature, Symbols and Abbreviations. Authors should follow current numbers of the British Journal of Nutrition in this connexion. The chemical nomenclature adopted is that followed by the Chemical Society (see J. chem. Soc. 1936, p. 1067 and Mitchell, A. D., 1948, British Chemical Nomenclature. London: Edward Arnold and Co.). For the nomenclature of amino-acids Brit. J. Nutr. 1953, 7, 1, should be consulted. With a few exceptions the symbols and abbreviations are those adopted by the Symbols Committee of the Royal Society in 1951 (Symbols, Signs and Abbreviations Recommended for British Scientific Publications, obtainable from the Chemical Society, Burlington House, London, W. 1). Of the exceptions, one of the most important is that the British Journal of Nutrition continues to use Cal. for the kilogram-calorie (instead of kcal). B.M.R. may be used for basal metabolic rate or basal metabolism.

Spectrophotometric terms and symbols are those proposed by the Society of Public Analysts and other Analytical Chemists (see Analyst, 1942, 67, 164). For mathematical notation and numerals the rules laid down in Proc. roy. Soc. A, 1909, 82, 14, should be followed. The attention of authors is particularly drawn to the following symbols: $\mathrm{m}(=$ milli $)=10^{-3}$ and $\mu(=$ micro $)=10^{-6}$. Note also that ml. (millilitres) should be used instead of c.c., and $\mu \mathrm{g}$ (micrograms) instead of $\gamma$.

Proofs. Proofs are sent to authors in order that they may make sure that the paper has been correctly set up in type, and not that they may add new material. Otherwise increased printing charges are inevitable. Excessive alteration may have to be disallowed. The symbols used to indicate corrections should be those laid down in British Standard 1219: $1945(2 s .6 d$.$) ; a shortened version is also published$ (B.S. $1219 \mathrm{c}: 1945,6 d$.$) .$

Reprints. Where at least one author of a paper is a member of The Nutrition Society, twenty-five reprints are supplied free of cost. Additional reprints may be purchased if the Press are notified on the appropriate form immediately the proof of the paper is received. 